\title{
Esclareciendo la historia de nuestra deuda externa: del Contrato Dreyfus a la Guerra del Pacifico*
}

Héctor Omar Neojovich Ch.

Nuestro propósito es despercudir de elementos ideológicos la historia del proceso, que Arnaldo Márquez tipificó como «orjia financiera» (1888) y que Revilla denominó como «frenesí de préstamos» (1991). En efecto, nos encontramos en general, con posiciones que enfrentan a los consignatarios del guano como una élite aristocrática (cf. Bogardus, 1866) opuesta a los intereses de la población (cf. Bonilla, 1974); frente a ello, en 2008 publicamos con el colega Alfredo Vento un análisis estrictamente económico financiero del proceso, alguna de cuyas conclusiones formarán parte del presente texto.

El meollo del problema lo ubicamos entre 1865-1869, desde la creación de la Compañía Consignataria del Guano y el empréstito Thompson Bonar seguido luego con el mentado Contrato Dreyfus y, por ello realizamos una investigación en archivos franceses, cuyos resultados generaron diversos trabajos (Noejovich y Vento, 2009, 2014; Noejovich, 2013, 2014, 2015, 2016). La cuestión llevó a un default de 1875, seguido de los reclamos de Dreyfus, de otros contratos de guano, la nacionalización del salitre y finalmente la infausta guerra del Pacífico. Con el Tratado de Ancón, en 1883, se estipularon obligaciones por parte del Gobierno chileno a favor de los acreedores externos que aparentemente se solucionó con el protocolo Donoughmore-Aspíllaga y su culminación el mentado Contrato Grace.

Sin embargo, esa negociación de la deuda externa alcanzó solamente a los tenedores sindicalizados en Gran Bretaña (Russell y Croydon), quedando fuera de ese arreglo acreedores de Europa continental. Eso condujo a un acuerdo franco-chileno para ventilar las reclamaciones ante un Tribunal Arbitral Franco-Chileno que funcionó

* Una primera versión fue presentada en el Congreso de Economistas, Lima, 6 de agosto de 2016. JEL: N26.

** Pontificia Universidad Católica del Perú, hnoejov@pucp.edu.pe 
en Lausana y emitió su fallo en 1902, con la oposición del Perú (cf. Araníbar, 1902) Subsistiendo reclamaciones, en 1914 la Cancillería peruana acordó con la francesa un protocolo arbitral ente el Tribunal de La Haya, que concluyó recién en $1921^{2}$, con un compromiso de pago por parte del Perú, que finalizó en $1926^{3}$. Como veremos fue un complicado periodo de medio siglo que, a nuestro parecer, no ha sido enfocado integralmente, con criterios técnicos, tanto económicos como jurídicos.

\section{LAS FINANZAS PÚBLICAS ${ }^{4}$}

Una indudable herencia del Estado colonial era el concepto de «regalías de la Corona», aplicado a los bienes «sin dueño» (res nullus para el derecho romano). Ese concepto fue ampliamente aplicado en casos como el andino, donde se discutía sobre la "propiedad conocida de los indios». Desde esta perspectiva las finanzas coloniales, fueron esencialmente «rentistas», especialmente respecto de la actividad minera y la población indígena; parecido criterio se aplicó a los «estancos», monopolios estatales sobre determinados productos 5 . Las del Estado republicano siguieron la misma tónica, con las «rentas de aduana» y el tributo indígena; esos conceptos doctrinarios se aplicaron luego al guano y al salitre. El manejo de las finanzas públicas sobre la base de «rentas» es criticado por Rodríguez:

El impuesto fue una fuente cegada en toda la primera época de la Historia financiera del Perú y desde 1845 fue sustituido en gran parte por el producto del huano.

El empréstito fue el objetivo de las finanzas sobre la base del rico filón del huano; de manera que el Perú presenta este fenómeno financiero no contemplado hasta hoy en nación alguna: el empréstito sin impuesto, es decir el empréstito levantado sobre base que nada en lo absoluto costaba al contribuyente (Dancuart y Rodríguez, 1912, XI, p. 9, cursiva en el original).

\footnotetext{
1 La documentación no es clara. La biografía de Grace menciona una deuda con los «bondholders» de $£ 51^{\prime} 000,000$ (James, 1993, p. 226). En la sentencia del Tribunal Arbitral se menciona $£$ 1’000,000 aproximadamente + el 50\% de las exportaciones a partir del Decreto de Escala ratificado por el Gobierno chileno y el Tratado de Ancón. (Cf. Tribunal Franco Chilean, 1987: Sentencia del Tribunal Franco-Chileno, 1902). El Tribunal de la Haya en 1921 estableció una compensación de FF 25’000,000 a favor de acreedores franceses, principalmente Dreyfus (Boletin MREE XI-LII, p. 179 y ss.)

2 Boletin MRREE, XI-LII, 1914: pp. 179 y ss.

3 RREE, Boletines: 67-E3*B5; 68-70-43-85; 68-70-P533.1.B; 55.1M 1923

4 El presente apartado reproduce, en parte, información y elaboración cuantitativa originada en Noejovich y Vento (2009).

5 Como por ejemplo la sal, el tabaco, los timbres, la pólvora, el papel sellado y otros productos.
} 
Esta es una visión precisa del "Estado rentista» bajo el cual tipificamos las finanzas peruanas con anterioridad a la guerra del Pacífico ${ }^{6}$. Las cifras que surgen del Cuadro 1 son demostrativas de la situación:

\section{Cuadro 1. Evolución de la recaudación fiscal}

Perú 1830-1862

\begin{tabular}{ccccccc}
\hline \multirow{2}{*}{ Año } & \multicolumn{2}{c}{ Ingresos fiscales } & \multicolumn{2}{c}{ Aduana } & \multicolumn{3}{c}{ Tributo indigena } \\
\cline { 2 - 7 } & Miles de pesos & $\%$ & Miles de pesos & $\%$ & Miles de pesos & $\%$ \\
\hline $1830-1831$ & 5290 & 100 & 2587 & 48.9 & 1638 & 31,0 \\
$1846-1850$ & 29563 & 100 & 10,188 & 34.5 & 6465 & 21,9 \\
$1851-1856$ & 70455 & 100 & 15,655 & 22.2 & 6857 & 9,7 \\
$1857-1862$ & 121145 & 100 & 18,995 & 15.7 & --- & -- \\
\hline
\end{tabular}

Fuente: Gootenberg (1989). Elaboración propia.

Como se aprecia del cuadro anterior, con anterioridad a la denominada «era del guano» — aproximadamente a partir de 1840 —, el presupuesto fiscal del Estado peruano se sustentaba en las «rentas de aduana» y la "contribución indígena», dejando un espacio cubierto por los estancos y licencias. Inicialmente el negocio del guano comenzó con un sistemas de sociedad, para pasar a un sistema de licencias y, finalmente, desembocar en el sistema de consignaciones (cf. Levin, 1964) conforme a la aprobación por parte del Congreso del contrato celebrado con la casa Anthony Gibbs \& Sons en 1849, el mismo que dejó a salvo la preferencia a los «hijos de país». Como consecuencia se fundó la Compañía Nacional de Consignatarios del Guanos cuyo gerente fue Manuel Pardo, luego el primer presidente civil del Perú.

Entre 1852 y 1853 , el presidente José Rufino Echenique, organizó una consolidación de la deuda interna, emitiendo bonos para rescatar todos los vales de requisas efectuados en la época de la guerra de la Independencia y posteriores, con el consiguiente escándalo por supuestos fraudes (Quiroz, 1987), los mismos que fueron convertidos en bonos externos (Levin, 1964, p. 89) obviamente para evitar las acciones judiciales locales. La resolución del Congreso, antes citada, no llegó a concretarse sino en 1862, año en el cual una licitación para un nuevo contrato fue adjudicada a la Compañía Nacional de Consignatarios del Guano, anteriormente citada (cf. Palacios Moreyra, 1983, pp. 90 y ss.). Como la sociedad no tenía la capacidad financiera necesaria, recurrió a una asociación con la empresa inglesa Thompson Bonar \& Co., quienes gestionaron el empréstito de 1865 , siempre para aliviar las finanzas públicas.

El Estado peruano devino en el más endeudado de América Latina como puede apreciarse en el Cuadro 2:

\footnotetext{
6 Recién hubo intentos después de la guerra del Pacífico, con impuestos a los sueldos, a la renta eclesiástica, otorgamiento de patentes y otros, pero recién en el siglo XX comienza a ordenarse la tributación con el impuesto a la exportación en 1915 (ley 727) y finalmente un impuesto a la renta en 1927 (ley 5574).
} 
Cuadro 2. Valor nominal total de préstamos externos en América Latina, 1850-1875 En miles de libras esterlinas

\begin{tabular}{lccc}
\hline \multicolumn{1}{c}{ Paises } & Importes \\
\hline Argentina & 13488 & \\
Brasil & & 23647 & \\
México & 16960 & \\
Perú & & & 51840 \\
Otros & 35131 & & \\
& 35131 & 54095 & 51840 \\
\hline Participación & $25 \%$ & $38 \%$ & $37 \%$ \\
\hline
\end{tabular}

Ello fue consecuencia de la política financiera de recurrir al endeudamiento antes que la imposición, creando una sensación falsa de prosperidad. En su memoria de fecha 29 de julio de 1864, el ministro de Hacienda, Ignacio Noboa señalaba:

... que las entradas de la República no guardan relación con sus gastos, que aquellas no ascienden por término anual a más de diez y seis millones de pesos, mientras que los segundos suben, en la misma proporción, a veinte y cuatro millones de pesos. El guano vendido hasta el presente y el que se venderá aún por mucho tiempo, nunca dará un producto neto de más de doce millones... de las clarísimas observaciones que acabo de hacer que el Perú, en su estado normal, tiene que sufrir anualmente un déficit real y permanente de más o menos ocho millones de pesos (cit. Palacios Moreyra, 1983, pp. 96-97).

El proceso de endeudamiento y sus consecuencias se visualizan en los siguientes gráficos y cuadros:

\section{Gráfico 1. Deuda pública acumulada}

Perú (1822-1878)

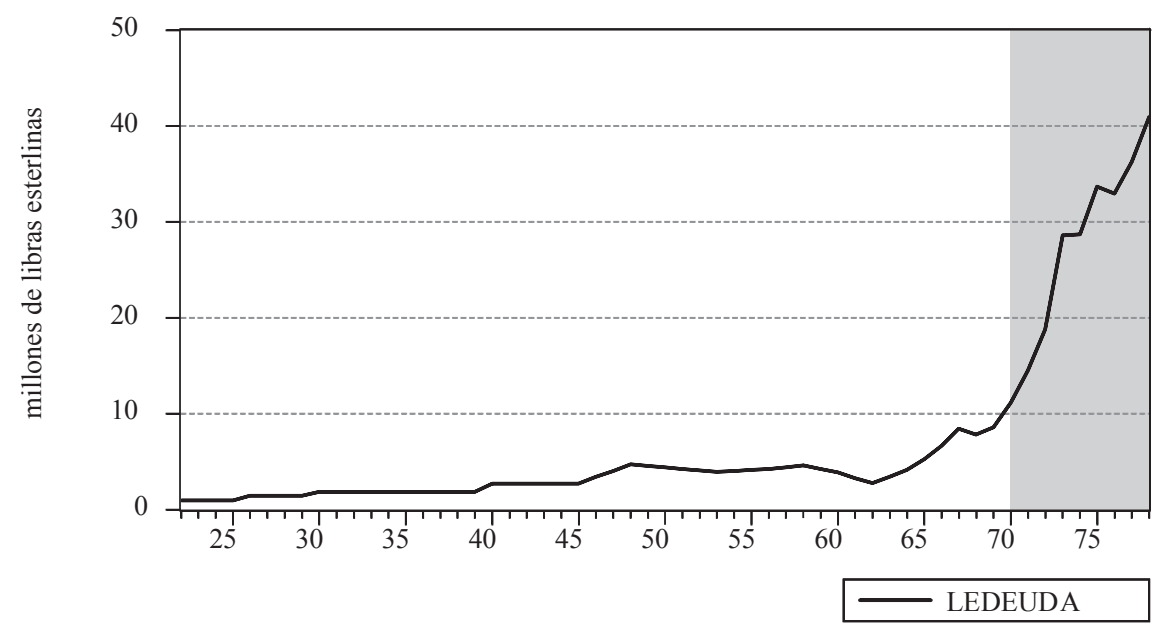

Fuente: Tantaleán (1991, p. 49). Elaboración: Noejovich y Vento (2009). 
La evidencia estadística que denota el gráfico anterior muestra, sin lugar a dudas que el endeudamiento se genera a partir del denominado Contrato Dreyfus que analizaremos en detalle en el capítulo siguiente; no obstante el empréstito Thompson Bonar produjo, con anterioridad un leve aumento, al refinanciar deudas preexistentes. En efecto, la colocación de bonos se realiza a través de un agente financiero que toma la totalidad de la emisión y luego la coloca en los inversores finales, de tal manera que existe una prima a cargo de la entidad emisora, en nuestro caso el gobierno peruano ${ }^{7}$. La consecuencia es una "prima de emisión» que eleva los intereses nominales como podemos apreciar en el cuadro 3 .

Cuadro 3. Términos de contratación de los empréstitos $(1822-1872)^{8}$

\begin{tabular}{cccc}
\hline AÑO & $\begin{array}{c}\text { TASA NOMINAL } \\
\% \text { anual }\end{array}$ & $\begin{array}{c}\text { COTIZACIÓN } \\
\% \text { s nominal }\end{array}$ & $\begin{array}{c}\text { TASA EFECTIVA ANUAL } \\
\text {-TEA \% }\end{array}$ \\
\hline 1822 & 6,00 & 75 & 9,13 \\
1826 & 6,00 & 83 & 9,19 \\
1849 & 6,00 & refinanciación & 5,70028 \\
1853 & 4,50 & 85 & 5,9972 \\
1853 & 4,50 & 85 & 6,2716 \\
1853 & 4,50 & 85 & 5,4951 \\
1862 & 4,50 & 93 & 5,8875 \\
1865 & 5,00 & $83,5^{10}$ & 5,3936 \\
1870 & 6,00 & 80 & 7,9061 \\
1872 & 5,00 & 75 & 7,3008 \\
\hline
\end{tabular}

Fuente: Tantaleán (1991). Elaboración: Noejovich y Vento (2009).

Como se puede apreciar los servicios reales se elevan notablemente con los empréstitos contratados a través de Dreyfus y que se explican, en parte ${ }^{11}$, por aquello que modernamente se denomina "riesgo país». En la actualidad se toma como referencia los bonos del Tesoro de EE.UU., cuyo rendimiento se considera "tasa libre de riesgo" (TLR); para el siglo XIX la referencia eran los «consols» británicos ${ }^{12}$. Pero la comparación debe hacerse con el verdadero costo del crédito, dado que en las nuevas emisiones se rescataban las anteriores a la par, absorbiendo así las primas de emisión de cada colocación, que nos da como consecuencia una tasa de interés real sobre los montos percibido (TIR), mucho mayor.

\footnotetext{
7 Actualmente se denomina underwriting a la operación que realiza esa suerte de «mayorista financiero».

8 El último empréstito fue el de 1872.

9 Fue una conversión de títulos a la par, con rebaja de intereses.

${ }^{10}$ Consolidó empréstitos anteriores a la par, mientras que la emisión de nuevos títulos fue colocada bajo la par.

11 Decimos «en parte» para dejar margen a una discusión sobre corrupción que reservamos para el siguiente capítulo.

12 Títulos de «renta perpetua» (no se pagaba el capital, solo intereses) que se originaron con la consolidación de la deuda interna a raíz de la Revolución Gloriosa de 1689.
} 
Veamos el gráfico 2:

Gráfico 2. Tasa interna real rendimiento de Consols-TLR prima real 1822-1878

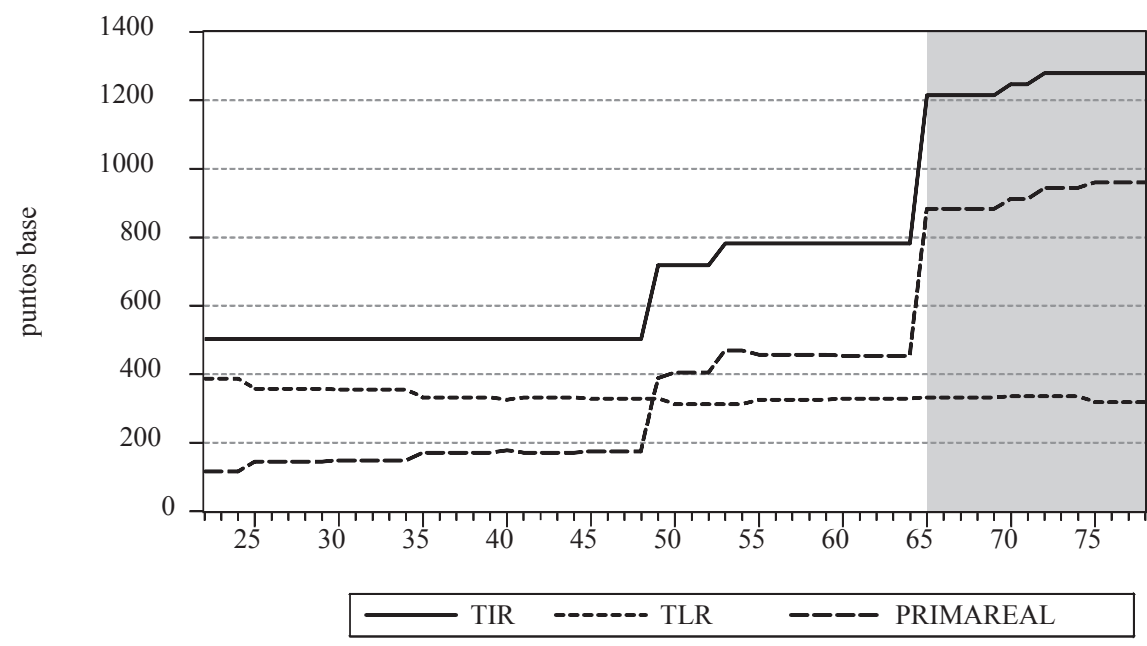

Fuentes: Noljovich y Vento (2009).

Como se aprecia del gráfico anterior, el aumento de la prima de riesgo país se eleva considerablemente a partir del empréstito Thompson Bonar y se acelera con las colocaciones de Dreyfus. Finalmente, la colocación del empréstito de 1872 quedó trunca por la crisis financiera en Londres y a continuación se puede apreciar el estado de las cuentas, en el cuadro 4:

Cuadro 4. Colocación, resultado y destino del empréstito de 1872 En libras esterlinas

\begin{tabular}{lrrlr}
\hline \multicolumn{1}{c}{ Origen } & Nominal & \multicolumn{1}{c}{ Neto $^{13}$} & \multicolumn{1}{c}{ Destino } & Importe $^{14}$ \\
\hline Vendido a Dreyfus al 75\% & 4000000 & 3000000 & Reembolso Dreyfus* & 1520109 \\
Suscripto por el público al 77 1/2\% & 2300000 & 178250 & Conversion 1865(132/100£) & 6268056 \\
Vendido a Dreyfus al 75\% & 2000000 & 1500000 & Reembolso Perú-Chile* & 13762 \\
Vendido a Dreyfus para el sindicato al 66\% & 1000000 & 660000 & Para ferrocarriles* & 5403131 \\
Vendido a Dreyfus al 60\% & 9500000 & 5700000 & Costo de emisión bonos 1872 & 1117241 \\
Ventas varias por Dreyfus al 60,855\% & 4220520 & 2568397 & Intereses a los bancos & 23070 \\
Ventas por el Banco del Perú al 63,652\% & 549400 & 349704 & A la orden de legación francesa & 20781 \\
Ventas por el Banco de Arequipa al 67,632\% & 160000 & 107779 & Saldo en poder de Dreyfus & 3481 \\
Ventas por el Bank of London, Mexico and & 470000 & 305500 & & \\
South America & & & & $\mathbf{1 4 3 6 9 6 3 1}$ \\
\hline TOTALES & $\mathbf{2 2 ~ 1 2 9 9 2 0}$ & $\mathbf{1 4 3 6 9 6 3 1}$ & TOTALES & \\
\hline
\end{tabular}

Fuente: Bonilla (1974, pp. 132-133), Tantaleán (1991, p. 45). Elaboración: Noejovich y Vento (2009, p. 28).

13 Suma correspondiente a la colocación bajo al par de los títulos.

14 Destino de los fondos netos resultantes. 
«De esta cifra, el Estado peruano solamente percibió £ 6’946,310 ${ }^{15}$ »

Seguidamente, a fin de proporcionar una visión comparativa, insertamos los gráficos 3 y 4 que nos darán una perspectiva del endeudamiento en relación con las exportaciones de guano y salitre. Como se aprecia a primera vista, el ingreso por las exportaciones de guano cae después del contrato Dreyfus, tomando auge el salitre. Además eso se refleja en el siguiente gráfico 4 en referencia a los ingresos estatales por guano.

Nuevamente la modificación es a partir del Contrato Dreyfus que veremos en el capítulo siguiente, no sin antes mostrar la diferencia con el caso del salitre, producto con el cual ambos comportamientos son congruentes, como lo denota el gráfico 5.

Gráfico 4. Guano: ingresos estatales y exportaciones

Perú: 1846-1876

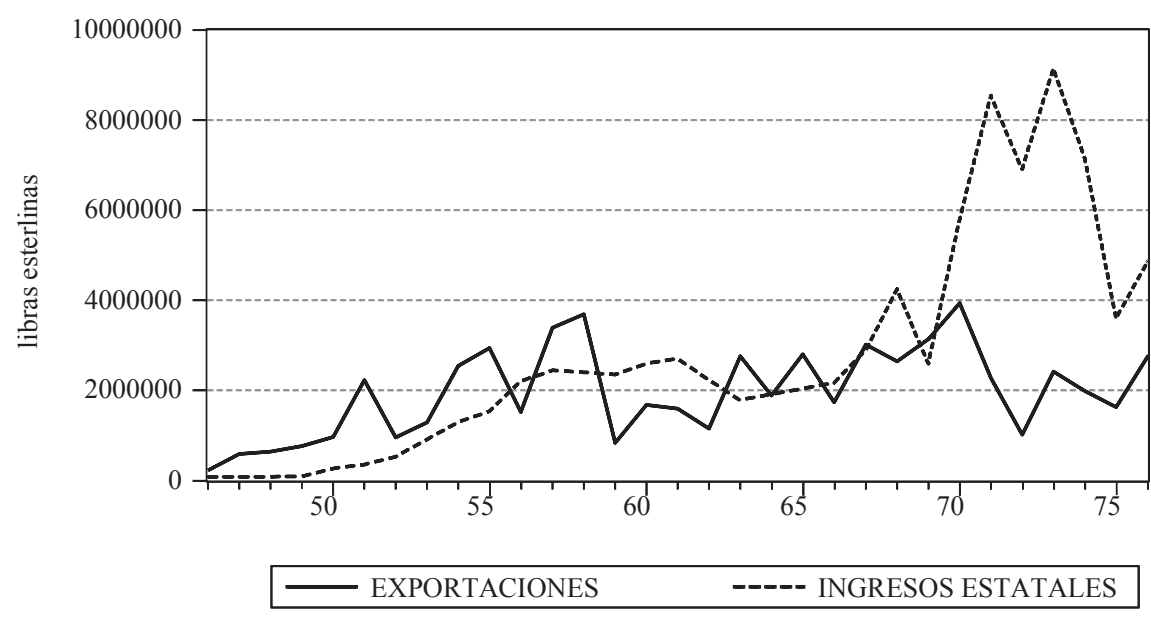

Fuente: Bonilla (1980, pp. 33, 43), Tantaleán (1983, cuadro 4). Elaboración: Noejovich y Vento, 2009.

\section{EL CASO DREYFUS}

El antecedente político, de este caso, podemos ubicarlo en la reacción política local frente a los concesionarios de guano y, especialmente, contra Manuel Pardo y la Compañía Nacional de Consignatarios del Guano, vinculada por razones financieras con Thompson Bonar, especialmente después del empréstito negociado con esa firma luego del combate del 2 de mayo de 1866. Las críticas están resumidas en dos artículos de Guillermo Bogardus $(1866)^{16}$, que están dirigidas especialmente a Manuel Pardo y las relaciones

\footnotetext{
15 Ibídem; el * identifica las cantidades efectivas recibidas por el Perú.

${ }^{16}$ Se carece de mayores referencias biográficas del autor y solamente podemos aportar las citas de Basadre (2005, VII, p. 32) sobre su premiación por el Congreso acerca de su denodada oposición a los consignatarios de guano, como asimismo su participación en la compra del Talisman junto a Piérola, nave que fue utilizada en la actividad insurreccional contra el presidente Pardo durante el mandato de este (pp. 238 y ss.)
} 
que mencionamos. Se basan en general a los costos de fletes, gastos y a posible ventas a testaferros, cuestiones frecuentes en las prácticas comerciales, aún en el mundo actual; frente a ello está siempre la aprobación de la rendición de cuentas por parte del comitente $^{17}$, hecho que no está referido en la denuncia ${ }^{18}$. Sin embargo con anterioridad hubo otros críticos, como señala Basadre (2005, III, pp. 201-209), tales como la denuncia de Carlos Barroilhet contra la Casa Gibbs; la Compañía General Marítima de París contra la Casa Montané; la de Luis Mesones que fue encargado de negocios en París contra los mismos. Ello tuvo como resultado, a instancias de José Gálvez, la ley del 9 de septiembre de 1857, con el nombramiento de comisionados fiscales para investigar sobre los precios del guano negociado por los consignatarios en Inglaterra, Francia y Estados Unidos.

José Balta asumió la presidencia en el mes de agosto de 1868; mientras tanto el Congreso nombraba una comisión investigadora de las denuncias formuladas por Bogardus. Por recomendación de José Rufino Echenique ${ }^{19}$, Balta nombró ministro de Hacienda a Nicolás de Piérola; este, cercano a Bogardus, era enemigo del sistema de consignaciones, que buscó reemplazarlo con el denominado Contrato Dreyfus. Un ingrediente importante para las ya maltrechas finanzas públicas fue la contratación con Enrique Meiggs para la construcción de ferrocarriles pagándole en bonos de la deuda pública; esto ocurrió cuando Piérola no era aún ministro. La cuestión de la deuda se había convertido en una cuestión política.

Piérola obtiene del Congreso, el 26 de enero de 1869 una autorización al Poder Ejecutivo: «....para que procure los fondos necesarios para salvar el déficit que resulta en el Presupuesto General de la República que debe regir en el presente bienio, dando cuenta al Congreso».

Con esa autorización y por decreto del 27 de marzo del mismo año se envía a Europa a los comisionados Toribio Sanz y Juan Manuel Echenique ${ }^{20}$ con instrucciones de encontrar comprador en firme de 2000000 t de guano; en tal sentido el 5 de julio de 1869 firmaron con la Maison Dreyfus et frères un contrato «ad-referéndum» del Congreso, que lo aprobó el 17 de agosto del mismo año, con algunas modificaciones indicadas por Piérola (cf. Noejovich, 2014, p. 5) a que hacemos referencia más adelante. Pero el mismo 5 de julio de 1869 , los comisionados firmaron con Dreyfus un "pacto secreto» ${ }^{21}$, centrado en los términos de liquidación de la relación con la firma Thompson Bonar, según convenio firmado con el ministro plenipotenciario y enviado especial don Federico Barreda el 18 de febrero de 1869 y, además, el sistema de anticipación de fondos hasta

\footnotetext{
17 Comitente es el que entrega la consignación; en este caso el Estado peruano.

18 Hay una defensa de Manuel Prado publicada por Evaristo San Cristóbal (1867-1922).

19 Había sido presidente del Perú (1851-1855) y derrocado por Castilla marchó al exilio en 1855 retornando al Perú en 1861; el padre de Nicolás de Piérola fue un «controvertido ministro de Hacienda (1852-1853) durante el corrupto gobierno de Echenique» (Quiroz, 2013, pp. 205-206). Fue durante su gobierno que se concretó la llamada "consolidación de la deuda interna (cf. Quiroz, 1987)

${ }^{20}$ Hijo de José Rufino Echenique.

21 BNP, Manuscritos, Colección Piérola.
} 
que se hiciese público el contrato definitivo. Quiroz (cf. 2013, p. 207, n. 39), además, enfatiza la existencia de anticipos de Dreyfus a Piérola, según carta de Guillermo Scheel a Piérola del 26 de mayo de 1869, evidenciado la existencia de una relación comercial previa a la firma del contrato entre el Gobierno peruano y la Maison Dreyfus et frères. Los consignatarios presentaron una demanda de retracto ${ }^{22}$ invocando el derecho de preferencia conforme a la ley de 1849, antes citada, respecto a los derechos de «los hijos del país». Si bien la Corte Suprema les dio la razón, el Gobierno no lo ejecutó y dejó en manos del Congreso de 1870 la resolución del problema.

\section{La Casa Dreyfus}

Respecto de la biografía de Auguste Dreyfus, a la cual nos referiremos brevemente. Nacido en Wissenbourg (Alsacia) el 28 de junio de 1827 y fallecido en París el 25 de agosto de 1897. De origen judío, se convirtió al catolicismo para casarse con Sofía Begrmann en 1862, quien falleció en 1871. Se casó nuevamente en 1873 con Luisa María González Orbegoso, nieta del mariscal Luis José de Orbegoso, quien fue presidente del Perú (1833-1836). Conforme a su libro de actas ${ }^{23}$ la sociedad Dreyfus et frères se constituye en París el 29 de agosto de 1852, entre los hermanos Prospero, Jerome e Isidoro Dreyfus para un comercio de telas, figurando Prospero como socio comanditario y sus hermanos como colectivos ${ }^{24}$. El 10 de noviembre de 1858 se acuerda la incorporación de Auguste a partir del $1^{\circ}$ de enero de 1859. Posteriormente se retira Prospero, en diciembre de 1863 e ingresa León el 12 de enero de 1864, retirándose Isidoro el 24 de enero de 1866; en consecuencia quedan solamente Auguste y León, prorrogándose la sociedad entre ellos hasta el 31 de diciembre de 1869.

Por su parte si bien Jerome aceptó con fecha 10 de abril de 1866 dejar su capital en la sociedad y el 19 de septiembre acordó transferir FF200 000 a Lima y percibir el 7\% anual. Un certificado médico de 4 de junio de 1869 acreditó la incapacidad física de León y con ese argumento el 11 del mismo mes y año, el Tribunal de la Seine declaró disuelta la sociedad entre Auguste y León. ¿Por qué esta secuencia de fechas? Tiene el propósito de discutir la validez del denominado Contrato Dreyfus, firmado el 5 de julio de $1869^{25}$, cuando la sociedad entre los hermanos estaba disuelta; ese fue el argumento de la representación peruana ante el Tribunal Arbitral Franco Chileno de Lausana.

\footnotetext{
22 Derecho que por ley o convención, se tiene para dejar sin efecto una venta o enajenación hecha a favor de otro y recuperar o adquirir para sí la cosa, por el mismo precio pagado y ciertos gastos ocasionados. Por su origen los retractos se dividen en convencionales y legales, según sea la voluntad de las partes o la disposición de la ley la causa de los mismos» (Cabanellas, 2006, V, p. 757)

23 AQ28.

${ }^{24}$ El socio comanditario es un aportador de capital sin injerencia en la gestión

25 Cf. Supra.
} 


\section{El CONTRATO Y EL SINDICATO}

Piérola formuló observaciones al contrato que fueron aceptadas por Dreyfus y como consecuencia el 17 de agosto de 1869 se emitió un decreto aprobatorio del mismo, con modificaciones, que incluyen cláusulas aparentemente contradictorias, que explicaremos y discutiremos en la siguiente sección, las mismas que fueron motivo de diferentes pleitos. Paralelamente, el 6 de julio de 1869, al día siguiente del contrato ad referendum firmado el día anterior con Toribio Sanz y José Manuel Echenique, Dreyfus constituyó una asociación denominada Sindicato del Guano, evidentemente en la búsqueda de financiamiento para la, a nuestro juicio, «osada compra», dado que carecía de la suficiente solvencia; sus asociados fueron Société Genérale y Leiden Premsel \& Co., reservándose una participación del $25 \%$ sobre un capital de 60’000,000 FF; cada participante podía ceder parte de sus participaciones a otros suscriptores ${ }^{26}$.

En ese orden de cosas, Dreyfus colocó aproximadamente 13,5 millones de francos, principalmente entre peruanos, tanto residentes en Europa como en Perú, de tal manera que su aporte efectivo fue mínimo respecto de sus socios; esta fue una evidente maniobra para "cumplir» con la ley de "preferencia a los hijos del país, que sin embargo no pudo evitar la acción de retracto presentada ante la Corte Suprema el 20 de agosto de 1869. Debemos agregar que el mencionado contrato contenía obligaciones de Dreyfus para el pago de los servicios de la deuda externa existente y el reconocimiento de las hipotecas sobre el guano derivadas del empréstito de 1865 con Thompson Bonar \& Co., señaladas expresamente en el contrato celebrado con esa firma

Las observaciones al contrato que efectuó Piérola, fueron aceptadas por Dreyfus y dieron lugar a un decreto aprobatorio el 17 de agosto de 1869, con modificaciones ${ }^{27}$, que incluyen cláusulas aparentemente contradictorias que discutiremos luego en la siguiente sección.

\section{LAS CONTRADICCIONES DEL CONTRATO}

Pero un tema de profunda importancia, son las contradicciones del contrato que pasaremos a analizar toda vez que constituye un punto central de la discusión en la historiografía peruana y que está contenido en la frase de Bonilla (1973, p. 323): «el precio de venta fijado de común acuerdo fue de común acuerdo fue de doce libras y diez chelines por tonelada», eso se contradice con la afirmación del autor (p. 323) «...un contrato... de compra y venta de dos millones toneladas de guano». Para mejor apreciación del lector incluimos el texto de los artículos que sustentan la controversia ${ }^{28}$ :

\footnotetext{
26 AQ28; cf. Brouillet, 1878.

27 La sociedad estaba disuelta legalmente. (Cf. supra).

28 Fuente: Colección de los Documentos oficiales y otras piezas relativas al contrato celebrado por el Supremo Gobierno con los señores Dreyfus Hermanos y Ca. Lima, tomo I, 1869; en adelante Colección. Subrayado nuestro. Para un análisis detallado ver Noejovich (2014).
} 


\section{Artículo 5}

"Los compradores pagarán al gobierno treinta y dos soles cincuenta centavos, por cada tonelada efectiva de huano que reciban en las guaneras a bordo de los buques fletados por ellos: treinta y cinco soles cincuenta centavos por las que reciban de buques fletados por los actuales consignatarios hasta la terminación de sus contratos; y sesenta soles, por las que existan en los diferentes depósitos de los consignatarios, el día que expiren los respectivos contratos».

\section{Artículo 12}

«Los precios de venta fijados por este contrato serán pagados por huano de buena calidad corrientemente exportado de las Islas de Chincha ó vendido á (£12-10) libras doce, diez chelines. Las diferencias de alza o bajas que sobre ese precio se hubiesen fijado cuando principie á ejecutarse el presente contrato, ó se estableciesen después, no aprovecharán á los compradores sino en cuanto al premio establecido en la cláusula 14; ni se perjudicarán, pues tendrán que abonar al Gobierno el exceso que hubiese sobre $£ 12-10$, y este rebajará los precios, en proporción á aquellos en que haya de venderse el huano»

¿Era una compra-venta o una consignación disimulada? Esto llevó a una serie de pleitos en Europa, después del rompimiento con Dreyfus en 1875. Si tomamos en cuenta la cesación del pago de los servicios de la deuda a partir de 1875 por parte de Dreyfus, podemos comparar con los saldos reclamados por este al Gobierno peruano, conforme al Cuadro 5:

Cuadro 5. Cuentas de Dreyfus con el Estado peruano

\begin{tabular}{lr}
\hline Adelantos & $£ 14^{\prime} 410,000$ \\
Guano vendido (calculado a $£ 7.20^{29} / \mathrm{tm}$ ) & $£ 9^{\prime} 801,396$ \\
Saldo & $£ 4^{\prime} 608,604$ \\
Saldo reclamado por Dreyfus & $£ 4^{\prime} 576,852$ \\
\hline
\end{tabular}

De este rápido análisis, inferimos que el precio de £12-10 chelines, era aparente, como así también las supuestas comisiones por importes mayores; asimismo las cláusulas respecto de los fletes eran completamente inocuas. Desde ese ángulo el contrato era inviable como negocio y no justificaba la creación del Sindicato del Guano que mencionáramos anteriormente. Esta cláusula era incongruente con la compraventa y simula una consagración, toda vez que si hay un precio de compra y esta es la figura, el precio y condiciones que fije el comprador son ajenas al vendedor; en esto recae la diferencia con un contrato de consignación. El efecto correspondiente a la de venta de guano, según Dreyfus (1890, p. 3$)^{30}$ enfatiza que eran «compradores de guano y no consignatarios»; adicionalmente hemos calculado los flujos al precio de compra de 36 soles, - equivalente a $£ 7.20$ — , como indica el artículo 5 del contrato que hemos insertado ${ }^{31}$.

29 Conversión de los 36 soles señalados en el contrato como precio de la compraventa de guano.

30 En ese mismo documento, Dreyfus refiere 36 soles como precio de compra (p. 3).

${ }^{31}$ Cf. supra. 
Cuadro 6. Comparación de flujos del contrato Dreyfus ${ }^{32}$

\begin{tabular}{rcrcrcrr}
\hline año & $\begin{array}{c}\text { adelanto } \\
\text { soles }\end{array}$ & $\begin{array}{c}\text { equivalente } \\
£\end{array}$ & $\begin{array}{c}\text { servicio } \\
\text { en } £\end{array}$ & flujo en $£$ & $\begin{array}{c}\text { t a } 12.5 \text { en } \\
£ ~ T\end{array}$ & $\begin{array}{c}\text { t a } 7.20 \\
\text { en } £\end{array}$ & \multicolumn{1}{c}{$\begin{array}{c}\text { Guano a } \\
\text { Dreyfus }\end{array}$} \\
\hline 1869 & 4500000 & 900000 & 490000 & 1390000 & 111200 & 193056 & \\
1870 & 8400000 & 1680000 & 490000 & 2170000 & 173600 & 301389 & 30526 \\
1871 & 8400000 & 1680000 & 490000 & 2170000 & 173600 & 301389 & 221044 \\
1872 & 8400000 & 1680000 & 490000 & 2170000 & 173600 & 301389 & 192.083 \\
1873 & 8400000 & 1680000 & 490000 & 2170000 & 173600 & 301389 & 211527 \\
1874 & 8400000 & 1680000 & 490000 & 2170000 & 173600 & 301389 & 681032 \\
1875 & 8400000 & 1680000 & 490000 & 2170000 & 173600 & 301389 & 216984 \\
& & & & 14410000 & 1152800 & 2001389 & 1361305 \\
\hline
\end{tabular}

Fuente: Noejovich (2015).

El cuadro precedente, calculado al precio de 36 soles por tonelada métrica no cubría los adelantos y aún con una mayor cantidad de guano dejaba siempre al Perú siempre con saldo a favor de Dreyfus, que este transfería al Sindicato del Guano ${ }^{33}$.

\section{El ROL DE AGENTE FINANCIERO}

El 31 de diciembre de 1869, se promulgó un decreto otorgando a Meiggs la conformidad para la construcción de los ferrocarriles Arequipa-Puno y Lima-La Oroya, que serían pagaderos en bonos por un total £ 11920 000. Piérola que había renunciado el 23 de octubre de 1869, una vez finalizado el contrato Dreyfus para la venta de guano, fue llamado nuevamente para el asumir el despacho de Hacienda, el mismo que asumió el 26 de febrero de 1870, manifestando su desacuerdo con la operación efectuada con Meiggs (Palacios Moreyra, 1983, pp. 124 y ss.). Bajo esa tesitura, el representante peruano, José María de la Torre y Bueno celebra con Dreyfus en París, el 19 de mayo de $1870^{34}$, un contrato facultándole a la emisión de bonos por $56^{\prime} 000,000$ soles $^{35}$; sobre esa base, Piérola negocia con Meiggs comprarle los bonos en su poder, mediante descuentos, según contrato celebrado en Lima el 6 de julio de $1970^{36}$.

\footnotetext{
32 Han sido convertidas las cifras de adelantos a libras esterlinas y de allí todos los flujos; es una demostración numérica que el contrato de 2000000 t de guano solo se cumplía a 36 soles, —equivalente a $£ 7.20$ -

33 ANF, AQ28. Un análisis de los estados financieros de esta asociación, que tenemos en proceso, arrojarán seguramente respuestas a las observaciones que estamos señalando.

34 En su Memoria a la Legislatura para la emisión de 1870 mediante el citado contrato, Piérola argumentó: «. ..que puedan servir de medio para transportar a nuestro suelo el capital extranjero, que tanto a menester aquel para su desarrollo; que por fin y cuando menos, deje expeditos a nuestro capitalistas para emplear su dinero, fuera de la esfera de la acción del Gobierno, en empresas lucrativas, por más provechosas y útiles al país, social, política y económicamente» (Tantaleán, 1991, p. 41; cursiva nuestra)

$35 £=5$ soles.

36 Dado que estamos privilegiando el discurso histórico desde un ángulo político y jurídico, omitimos los detalles del análisis financiero, para el cual nos remitimos a Noejovich y Vento (2009) y al capítulo anterior.
} 
La actitud de Piérola, retirarse del despacho de Hacienda una vez terminado el Contrato Dreyfus de compraventa de guano, para retomarlo un par de meses después de la adjudicación a Meiggs ${ }^{37}$ de las obras citadas para luego en menos de tres meses trasladar la operación financiera a Dreyfus despertó suspicacias, especialmente teniendo en cuenta la publicación hecha en París por el mismo Augusto Dreyfus como la siguiente: «Es inexacto que de la caja de Dreyfus hayan salido fondos para revoluciones, así como lo es que Señor Piérola sea sus socio. No basta acusar; es preciso probar» (Dreyfus, 1890, p. 11).

En enero de 1871 el Congreso autorizó la emisión de un nuevo empréstito para la conversión de los empréstitos existentes, en mérito del cual Piérola y Fort celebraron un convenio el 7 de julio de $1871^{38}$ para emitir un nuevo empréstito por $€ 15000$ 000; a fines de diciembre de 1871, el mismo que fue modificado por el comisionado en París, Melitón Porras, aumentado a $§ 36800$ 000, convenio que convalidó el nuevo ministro de Hacienda, Felipe Masías, en Consejo de Ministros el 12 de enero de 1872 (Basadre, 2005, VII, 16-17). Este empréstito no pudo ser ejecutado en su totalidad, en parte por la «burbuja financiera» de esos años y las consecuencias de la guerra franco-prusiana, quedando inconclusos los rescates programados y cuya rendición de cuentas, por parte de Dreyfus, fue el origen de problemas posteriores ${ }^{39}$.

\section{LA RUPTURA}

En el crucial año de 1872, se produjo un golpe de Estado, siendo derrocado y asesinado el presidente Balta, para luego pasar a una convocatoria a elecciones, resultando electo el presidente civil del Perú y fundador, también, del primer partido político: el civilismo y su jefe Manuel Pardo. Este, enemigo de Piérola, renegoció el contrato con Dreyfus en 18 de abril de 1874, dejando firme el contrato de venta sobre el guano, comprometiéndose este último al l pago de los servicios de la deuda solamente hasta el 1 de julio de 1875 . Se puso fin al monopolio de la venta de guano, pero se autorizó en el convenio la posibilidad que Dreyfus diluyera el guano (cf. Anónimo, 1903) ${ }^{40}$.

No obstante, el 23 de abril de 1873, Dreyfus había establecido una sociedad con Dionisio Derteano Echenique, Federico Fort y Guillermo Schell, como sucursal en Lima de la Maison Dreyfus et frères ${ }^{41}$, aportando él mismo la cantidad FF 5000000 y sus socios FF 250000 cada uno. En este estado quedaron las relaciones con Dreyfus hasta la dictadura de Piérola y continuaron los pleitos como veremos más adelante.

\footnotetext{
37 En ese contrato recibiría en pago bonos que él —Meiggs - debería negociar. Piérola renegoció el contrato con Meiggs, arguyendo que «era peligroso poner en manos del contratista el crédito del país» (Palacios Moreyra, 1983, p. 124).

38 Nuevamente Piérola renuncia el 21 de julio de 1871.

39 Para mayores detalles numéricos, ver capítulo anterior.

${ }^{40}$ La posibilidad de diluir el guano había sido anticipada por De Monniers (1845).

41 AQ28.
} 


\section{DE LA RUPTURA CON DREYFUS A LA GUERRA DEL PACIFICO}

De inmediato con el propósito de solucionar el pago del servicio de la deuda correspondiente al segundo semestre de 1875, el Gobierno peruano obtuvo facultades de la Legislatura y en virtud de ello el inspector fiscal del Perú en Europa, Lino Mariano de la Barreda ${ }^{42}$, suscribió con la Société Générale y el Anglo Peruvian Bank Ltd. el 1 de junio de 1875, para que estos abonaran el servicio de 1876, a cambio de $300000 \mathrm{t}$ de guano, en el caso que antes el Gobierno Peruano no hubiese celebrado un contrato para la exportación del guano antes del 31 de octubre de 1875. En el contexto aparente de una estrategia global, por Ley del 11 de mayo de 1875, una Legislatura extraordinaria había autorizado al Gobierno para vender 2000000 t de guano para cubrir servicios de la deuda externa y déficits presupuestarios (Basadre, 2005, VII, p. 163). Como consecuencia, los comisionados Fernando Rosas y Emilio Althaus fueron enviados a Francia a celebrar un nuevo convenio, ante el rechazo del anterior (Basadre, 2005, VII, p. 164); Althaus firmó un nuevo contrato con Société Générale el 28 de junio de 1875 en los términos generales siguientes ${ }^{43}$ :

- 1900000 t de guano consignado a la Compañía Consignataria del Perú.

- Será efectivo a partir del 1 de noviembre de 1876 , fecha en que se termina el contrato de guano con Dreyfus.

- Este contrato terminará el 31 de octubre de 1881.

Las ventas no deberán perjudicar los $2000000 \mathrm{t}$ adquiridas por Dreyfus

La etapa siguiente fueron una serie de telegramas cursados entre la Legación de Paris y Lima de los cuales hacemos hincapié en los siguientes (Palacios Moreyra, 1983, pp. 144-178).

Cuadro 7. Telegramas intercambiados entre París y Lima

\begin{tabular}{|c|c|c|}
\hline Fecha & Desde & Contenido \\
\hline 5.11 .1875 & Lima & Aprobación sujeta a especificación de $£$ por $\mathrm{t}$ y gastos asumidos \\
\hline 10.11 .1875 & París & $\begin{array}{l}\text { No fueron estipulados. Contrato celebrado con plenos poderes. Denunciado } \\
\text { convenio con Anglo Peruvian Bank Ltd. }\end{array}$ \\
\hline 11.11 .1875 & París & Por orden nuestra Société Genérale entregó a Pedro Gálvez 600000 FF ${ }^{44}$ \\
\hline 12.11 .1875 & París & Renuncian a la representación ante las desautorización del Gobierno peruano \\
\hline 16.11 .1875 & Lima & Rechazo del contrato con Société Genérale \\
\hline
\end{tabular}

Fuente: Palacios Moreyra (1983, pp. 149-150). Elaboración propia.

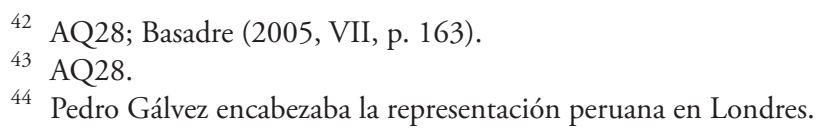


Nombrado José de la Riva Agüero, es invitado por Russell a viajar a Londres según carta del 20 de marzo de $1876^{45}$, dado que este se encontraba en París y no quería o no podía viajar a Londres, Russell ${ }^{46}$ envía a Alexander de Lasky presidente de la London Banking Association a buscar un consignatario que satisfaga los intereses de todos los «bondholders». Invocando la ley del 11 de mayo de 1875, Riva Agüero suscribe con Société Générale, el 31 de marzo de 1876 para la venta 1900000 t de guano destinado a Europa, Canarias y Australia, que comenzará el 1 de noviembre de 1876 bajo los términos siguientes ${ }^{47}$ :

- Se respeta el Contrato Dreyfus.

- Se mantiene la cantidad de 1900000 t.

- Anticipo al Gobierno peruano la suma de 10 chelines por t para gastos de carga.

- Los gastos hasta por la suma de $5 £ 8$ sh serán asumidos por Société Générale.

- El precio de venta se establece en $12 £ 10.8$ sh.

Se adelantaran $£ 700,000$ anuales comenzando en abril de 1876. La explicación que Riva Agüero dio al Gobierno peruano, con fecha 13 de abril de 1876, fue que el Comité de bonistas no había propuesto un consignatario aceptable. Una vez firmado el contrato antes citado, Riva Agüero no logra el acuerdo con Russel y el Comité rechaza el contrato con fecha 7 de abril de 1876 (cf. Dancuart y Rodríguez, 1902-1926, v. X, p. 68). El Gobierno peruano, nombra a Mariano Ignacio Prado, como representante, quien arriba a Londres el 24 de abril de 1876 para resolver el impasse generado con los tenedores de bonos frente al contrato con Société Genérale y luego de negociaciones con el Comité Russell suscribe un contrato con Raphael and sons, Carlos González Candamo y Arturo Heeren el 7 de junio de 1876, el mismo que es aprobado y suscrito por Russell el 10 de junio de $1876^{48}$. Resumimos las principales cláusulas, no sin antes subrayar el carácter de consignatarios del Gobierno peruano:

- Obligación de constituir la empresa «The Peruvian Guano Co. Ltd» con un capital no menor a $£ 800000$.

- El Gobierno peruano dará en consignación 1900000 t, exceptuando los mercados de Estados Unidos, Islas Mauricio y Antillas, China y Japón.

- Podrán comenzar con la ejecución del contrato celebrado a partir del $1^{\circ}$ de noviembre de 1876.

- Los fletes serán por cuenta y riesgo del Gobierno peruano.

- Los consignatarios adelantarán $10 \mathrm{Sh}$ al Gobierno peruano a cuenta del carguío.

\footnotetext{
45 AQ28.

46 Sir Charles Russell era presidente del comité de bondholders; adicionalmente hacia 1880 aparece otro comité, dirigido por James Croydon.

47 RREE S-17-G.

48 ANF, AQ28; Dancuart y Rodríguez (1902-1926, v. XXI, 68-73).
} 
- Los consignatarios cargarán en cuenta $£ 4.15$ por $\mathrm{t}$ siempre que el flete fuese menor a $£ 3.10$; si fuese mayor cargarán la diferencia.

- El precio se fija en $£ 1210$ sh.

- Se respetará el Contrato Dreyfus ${ }^{49}$.

- Las cuentas entre los consignatarios y el Gobierno peruano gozarán un interés recíproco del 5\%, salvo si el tipo fijado por el Banco de Inglaterra fuese mayor en cuyo caso de aplicará la tasa de este

- El guano garantiza los adelantos

- El adelanto anual que los consignatarios girarán al Gobierno peruano será de $£ 700,000$.

El excedente, deducidos gastos y adelantos, los consignatarios deberán depositarlos en el Banco de Inglaterra, para ser aplicado de la deuda externa, de conformidad con los tenedores de bonos cuyo representante aprueba el presente contrato. Cabe la pregunta ¿cuál era el beneficio del consignatario? Parecería más o menos evidente que su beneficio debería venir del lado de los bonistas y/o de un mayor precio del guano. Queda abierto el interrogante.

Se presentó otra situación cual fue la protesta de tenedores de bonos no representados por el comité Russell sino por otro liderado por James Russell. Esta dicotomía se evidenció durante la guerra, al ser ocupada Tarapacá por el general Erasmo Escala del ejército chileno quien emitió el siguiente decreto el 22 de febrero de 1880 en su calidad de comandante de las fuerzas de ocupación chilena, que transcribimos en las partes pertinentes:

Artículo primero: Se permite a los portadores extranjeros de bonos peruanos extraer guano de los depósitos del Perú ocupados por los ejércitos chilenos bajo las condiciones siguientes:

$1^{\circ}$ Los portadores de bonos designaran un Comité o una casa importante y segura que tome a su cargo los fletes y las operaciones de carguío.

$2^{\circ}$ El Gobierno de Chile intervendrá en esa elección; él se reserva de nombrar uno o varios funcionarios que harán la inspección superior y a la necesidad de la dirección (si ellos creyeran oportuno) las operaciones de la extracción y carguío.

$3^{\circ}$ Una vez que los navíos estén cargados, los nombrados inspectores, los harán partir para Valparaíso; estos navíos no partirán con destinación al extranjero, sino antes de abonar previamente pagar a la aduana de ese puerto el derecho de 30 chelines por tonelada de guano a bordo.

$4^{\circ}$ Los pagos se efectuaran en giros sobre Londres acordados por Chile y a su orden; él será reducido a 20 chelines en el caso de que el guano en los mercados de consumo descienda a $£ 6$ por tonelada.

\footnotetext{
49 Resulta obvio que no se altera la compraventa con Dreyfus. Esto refuerza la interpretación que este último no era una consignación.
} 
Art.2: Los conocimientos de los navios serán hechos a la orden de la casa Baring Brothers \& Co., o de otra casa del mismo valor, en el caso que no haya entendimiento con la casa Baring para los consignatarios.

Esperando la conclusión del contrato de consignación, los dichos conocimientos, serán hechos a la orden del Ministerio plenipotenciario de Chile en Francia y de los señores James Croyle y Sir C. Russell.

Art. 3: Donde los consignatarios de guano procedieran a la realización de los carguíos arribados; ellos deducirán del producto los gastos ocasionados, ya sean por la gestión de haya motivado la presente autorización del permiso acordado por el presente decreto, ya sea por el pago, cuya referencia está en el artículo primero, ya sea por la extracción y transporte del guano a los mercados de consumo, ya sea por causas análogas, ellos repartirán el producto líquido entre los portadores de bonos peruanos que tuviesen una hipoteca constituida a su favor sobre los depósitos de guano ${ }^{50}$.

El Gobierno chileno ratificó la resolución de escala por decreto del 2 de marzo de 1880, hecho que dio origen a protestas, tanto del gobierno peruano como de Dreyfus; no obstante, según documentación contable de Dreyfus ${ }^{51}$, este comenzó a comerciar con salitre durante la guerra y continuó haciéndolo luego. Finalmente no podemos dejar mencionar la misión Rosas-Goyeneche (Rosas, 1881), enviada por el entonces presidente Prado a negociar un nuevo contrato para la venta del guano. Estos lo verificaron con Crédit Industriel el 7 de enero de 1880; este contrato fue anulado por Piérola quien celebró un arreglo con Dreyfus ordenándoles el endoso de los conocimientos de embarque a favor de este (Rosas, 1881; Noejovich, 2014).

\section{REFLEXIONES CONCLUSIVAS}

El punto inicial de la crítica entiendo que debe enfocarse en los aspectos técnicos: económicos y jurídicos. Desde el aspecto económico, los empréstitos contratos con Dreyfus configuraron un verdadero despojo por los términos de colocación, especialmente agravados por el rescate por el valor nominal de empréstitos anteriores que habían sido colocados con primas muy altas. Esto sugiere un negociado de envergadura para los intervinientes y/o un pésimo manejo de los encargados nacionales de las finanzas. Si bien existía una confrontación con el sector consignatario guanero, las críticas sobre este se referían a comisiones, fletes, precios de venta y otros detalles menores frente a primas del 25\% que se utilizaron para rescatar empréstitos anteriores a la par.

Pero igualmente es criticable la errónea interpretación del Contrato Dreyfus, como la efectúa Bonilla, cuya contradicción es evidente (1973, p. 323) ya que en efecto menciona por una parte: «El precio pagado por Dreyfus al Gobierno era de S/36,50 por cada

50 Hemos subrayado temas que surgirán en el proceso de Lausana.

51 ANF, AQ28. 
tonelada tomada de las islas guaneras...» Y por la otra agrega: "El precio de venta fijado de común acuerdo fue de doce libras y diez chelines por tonelada...precio que Dreyfus no podía modificar sin previo acuerdo....»

Esto es una contradicción a la naturaleza contractual de la compraventa ${ }^{52} \mathrm{y}$, a nuestro juicio, pretendía simular una consignación probablemente con motivos políticos, y en ese sentido favoreció a la interpretación historiográfica enfocada en la "lucha de clases». Así, Bonilla (ibídem, 328) menciona, acerca de los consignatarios «el pillaje a que anteriormente habían sometido a las finanzas peruanas»; afirmación errónea que no se condice con el análisis económico que presentamos a un inicio, donde el gran deterioro de las finanzas provino realmente de las «primas de emisión» (cf. supra).

Finalmente la afirmación del autor citado (ibídem, 317) «...a través de la apropiación de los capitales del guano, se inició el fortalecimiento económico y político de la élite comercial-terrateniente...». Esta afirmación no se corrobora con el análisis financiero el que, más bien, cuestiona la relación Piérola-Dreyfus. Esta última requiere un análisis más exhaustivo y despercudido, en la medida de lo posible, de apreciaciones tipo oligarquía versus burguesía. Esta última es una «asociación» que debería ser revisada exhaustivamente por la historiografía, quitando los prejuicios acerca de una oligarquía a la que más bien le cabe el calificativo de plutocracia y no tanto el sentido del poder político.

En efecto, el acceso al poder de Pardo y el partido civilista apuntó hacia una modernización del sistema financiero y, especialmente en la comercialización de los productos primarios, como guano, salitre y el incipiente cultivo de azúcar. Quedan estas cuestiones abiertas a la críticas, comenzando, repetimos, por los aspectos económicos y jurídicos.

\section{FUENTES}

1852-1897 AQ28 La Maison Dreyfus frères et Cie. Roubaix: Archives du Monde de Travail.

1897 Tribunal arbitral franco-chilien: Analyse de faits qui paraissent être admis par tous les partis. Lausana: Imprimerie George Bridel.

1902 Sentencia del Tribunal Franco-Chileno. Anexo a la Memoria de Relaciones Exteriores. Lima: Imprenta del Estado.

1902-1926 Dancuart, Pedro Emilio y José Manuel Rodríguez. Anales de la Hacienda Pública del Perú. 24 vols. Lima: Ministerio de Hacienda.

Ministerio de Relaciones Exteriores del Perú

Biblioteca Nacional del Perú

Colección de los Documentos oficiales y otras piezas relativas al contrato celebrado por el Supremo Gobierno con los señores Dreyfus Hermanos y Ca. Lima, tomo I, 1869.

\footnotetext{
52 Para un análisis detallado del contrato ver Noejovich (2014).
} 


\section{REFERENCIAS}

Anónimo (1903). La historia de la reclamación Dreyfus por un peruano. Mimeo. Bruselas.

Araníbar, José (1902). Exposición que José de Araníbar hace a su gobierno y a sus conciudadanos, para que conoscan (sic) la arbitrariedad de los actos y abusos del poder del llamado "Tribunal Arbitral Franco Chileno» constituido en Lausana y la injusticia, falta de verdad y nulidad de todos y decisiones. Lima: Imprenta calle de Quilca.

Basadre Grohmann, Jorge (2005). Historia de la República del Perú.1822-1933. Lima: El Comercio.

Bogardus, Guillermo (1866). Denucia hecha por el peruano Guillermo Bogardus sobre los abusos y estafas cometidas por los consignatorios del guano y algunos de los agentes diplomáticos y financieros de la República. Lima: Imprenta Liberal.

Bonilla, Heraclio (1973). Auguste Dreyfus y el monopolio del Guano. Revista del Museo Nacional, XXXIV. Lima.

Bonilla, Heraclio (1974). Guano y burguesía. Lima: IEP.

Brouillet, Philip (1878). Les emprunts du Pérou et les Syndicat Dreyfus-Premsel-Société General. París.

Cabanellas, Guillermo (2006). Diccionario enciclopédico de derecho usual. Buenos Aires: Heliasta.

Clarke, William (1877). Protesta hecha como representante de los tenedores de los bonos peruanos. Callao.

De Moniers, M.A.H. (1845). Guano du Pérou. París: Imprimerie et fonderie de Rignoux.

Dreyfus, Auguste (1890). Cuestion Dreyfus. París: Imprimerie et Libraire Centrales des Chemins de Fer.

Gootenberg, Paul (1989). Between Silver and Guano. Princeton, NJ: Princeton University Press.

James, Marquis (1993). Merchant Adventurer. The Story of W. R. Grace. Wilmington: A Scholarity Resources Imprint.

Levin, Jonathan (1964). Las economías de exportación. México: UTEHA.

Márquez, José Arnaldo (1888). La orjía financiera: el guano y el salitre. Santiago: Imprenta de la Libertad Electoral.

Noejovich, Héctor (2003). La noción abstracta de propiedad en América. Derecho PUCP, 56, 989-1014.

Noejovich, Héctor (2013). Política y finanzas públicas: el caso Dreyfus en el Perú del siglo XIX. En Alicia Gil Lázaro y Claudia Elina Herrera, El pensamiento liberal Atlántico 1770-1880. Fiscalidad en perspectiva comparada. Alcalá de Henares: IELAT.

Noejovich, Héctor (2014). In memoriam Alfonso Quiroz Norris (1957-2013) ¿Era viable el contrato Dreyfus? Economia, XXXVII(74), 249-270.

Noejovich, Héctor (2015). Los fertilizantes y la política fiscal: Perú, 1840-1890. Nueva Coronica, 5. Lima: Universidad de San Marcos.

Noejovich, Héctor (2016). Política y Finanzas públicas en el Perú del siglo XIX: el guano y el contrato Dreyfus. En Voluntarismo financiero y atraso económico en América Latina. México DF.: Universidad Autónoma de México.

Noejovich, Héctor Omar y Alfredo Vento (2009). Guano, salitre y finanzas públicas: el Pacífico en el siglo XIX. Documento de trabajo 273, CISEPA. Lima: PUCP,

Noejovich, Héctor Omar y Alfredo Vento (2014). Política y deuda pública en el Perú. Bicentenario. Revista de Historia de Chile y América, 13(1), 21-37.

Novak Talavera, Fabián (2005). Las relaciones entre el Perú y Francia (1827-2004). Lima: Fondo Editorial PUCP. 
Palacios Moreyra, Carlos (1983). La deuda anglo peruana 1822-1890. Lima: Librería Studium.

Quiroz, Alfonso (1987). La deuda defraudada: consolidación de 1850 y dominio económico. Lima: Instituto Nacional de Cultura.

Quiroz, Alfonso (2013). Historia de la corrupción en el Perú. Lima: IEP, Instituto de Defensa Legal.

Revilla, Julio (1991). Frenesí de préstamos y cese de pago de la deuda externa: el caso del Perú en el siglo XIX. Quito: Flacso.

Rosas, Francisco (1881). La verdad sobre el Contrato Rosas-Goyeneche y sobre los Contratos Piérola Dreyfus. París: Imprenta Hispano-Americana.

San Cristóbal, Evaristo (1922). Contestación de don Manuel Pardo a la denuncia de Guillermo Bogardus, precedida de un estudio histórico. Lima: Imprenta Gloria.

Tantaleán Arbulú, Javier (1991). La deuda externa peruana y el imperio inglés en el siglo XIX. Deuda Externa Latinoamericana. Cuadernos 2. Lima: Instituto para la Deuda Externa Latinoamericana. 